\title{
Point-Mutations in embB306 Gene and Their Association with Resistance to Ethambutol in Mycobacterium tuberculosis in Clinical Isolates
}

\author{
Bahman Mohammadi (iD), Rashid Ramazanzadeh $^{2}$ (D), Samaneh Rouhi $^{3}$ (D), \\ Parviz Mohajeri $^{4}$ iD), Bijan Nouri ${ }^{5}$ (D)
}

1. Student Research Committee, Kurdistan University of Medical Sciences, Sanandaj, Iran

2. Cellular and Molecular Research Center, Research Institute for Health Development, Kurdistan University of Medical Sciences, Sanandaj, Iran

3. Medical Microbiology Research Center, Qazvin University of Medical Sciences, Qazvin, Iran

4. Nosocomial Infection Research Center, Kermanshah University of Medical Sciences, Kermanshah, Iran

5. Social Determinants of Health Research Center, Research Institute for Health Development, Kurdistan University of Medical Sciences, Sanandaj, Iran

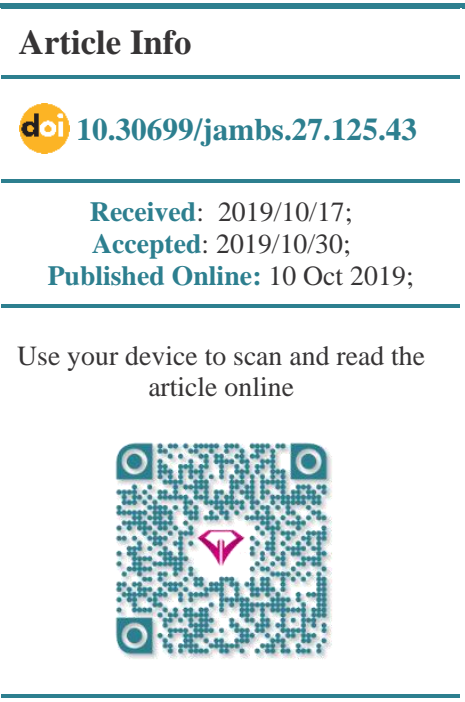

Corresponding Information: Bahman Mohammadi, Student Research Committee, Kurdistan University of Medical Sciences, Sanandaj, Iran

E-Mail: bahman.mo67@gmail.com

\section{ABSTRACT}

Background \& Objective: Mutations in $e m b$ B306 gene and their association with resistance to ethambutol (EMB) in Mycobacterium tuberculosis (M. tuberculosis) have not been fully investigated. The aim of this study was to investigate the pointmutations in $e m b 306 \mathrm{~B}$ gene and their association with resistance to EMB in $M$. tuberculosis.

Materials \& Methods: This case (M. tuberculosis resistant to EMB) -control (M. tuberculosis sensitive to EMB) study was performed in the West of Iran (2014-2015), in order to determine the sensitivity of $M$. tuberculosis strains. Polymerase chain reaction (PCR)-DNA sequencing was used for determining the point-mutations of $e m b \mathrm{~B} 306$ gene in both groups (sensitive and resistant to EMB). Data was analyzed by SPSS 16 and Fisher's exact test.

Results: Fifty M. tuberculosis strains were isolated from 1019 patients that were suspected to have tuberculosis (TB). $86 \%$ of the isolates were sensitive and $14 \%$ were resistant to EMB. EmbB306 gene sequencing showed no mutation in control samples; but mutation was observed in $85.71 \%$ of resistant samples in case samples. The embB306 mutation showed a significant relationship with EMB resistance $(P=0.00)$.

Conclusion: Mutations in $e m b \mathrm{~B} 306$ were observed in the strains resistant to EMB; however, there was no mutation in the sensitive group. There is a direct relationship between these mutations and this type of resistance, so it is an indicator of creation of resistance to EMB in M. tuberculosis.

Keywords: embB306 Gene, Ethambutol, Mycobacterium tuberculosis, PointMutations

\section{Introduction}

Occurrence and dispersion of multidrug-resistant (MDR) and drug-resistant (DR) strains of Mycobacterium tuberculosis (M. tuberculosis) are the biggest problems in tuberculosis (TB) treatment. Ethambutol (EMB) is a bacteriostatic drug that physicians have been using for treating TB since the mid1960s. Resistance to ethambutol (EMB) may cause resistance to other anti-TB drugs in $M$. tuberculosis cases (1). Different factors cause resistant to bacteria, one of which is mutation. Types of mutation are spontaneous mutations (occur without mutation induction and is the result of errors during DNA replication) such as silent mutation, missense mutation, nonsense mutation and mutation induction (mutagens may be of physical, chemical, or of biological origin) (2). The main mechanism of acquiring resistance to $\mathrm{EMB}$ in $\mathrm{M}$. tuberculosis depends on point mutations (nonsense mutation) in emb operon encoding arabinosyltransferase (point mutation or substitution is defined as a genetic mutation, in which a single nucleotide base is deleted, inserted, or changed in a DNA or RNA sequence. This type of mutation has different effects on the downstream protein product consequences that are predictable to a certain extent based on the specifics of the mutation). The emb operon encodes various arabinosyltransferases that include three adjacent genes (embC, embA, and embB) (3,4). Five different mutations have been found in this codon where translocations have intermittently occurred in the first 
or the third base (ATG to GTG, CTG, ATA, ATC, or ATT) (5). Mutations in embB497, embB406, and embB306 codons bring about moderate and low levels of EMB resistance (1). Having utilized direct sequencing and polymerase chain reaction-singlestrand conformational polymorphism (PCR-SSCP), Nasr Esfahani et al. demonstrated that out of $32 \mathrm{M}$. tuberculosis isolates, $6.25 \%$ had resistance to EMB and in 2 EMB-resistant isolates, mutations were observed on codons 309 and 299 (6). Ahmad et al. (2017) using PCR and sequencing, reported that out of 163 isolates, $19 \%$ were resistant to EMB and only 10 isolates showed embB mutation at either codon 281 or 306 , or both (7).

While having respect for the above-mentioned investigations, this relationship is unclear; because all of these codons have been mutated in some of the $\mathrm{M}$. tuberculosis that is sensitive to EMB. According to this contradictory result, it was decided to examine this gene once again in order to study the possible role of mutation in the created resistance to EMB. Variation in the prevalence of specific mutations in relation to resistance to EMB is likely to be due to different geographical areas. Rarely any research has been conducted on the relationship between point mutation and antibiotic resistance to EMB in the Western region of Iran. Moreover, many researchers disagree on the validity of this matter. Therefore, numerous studies in different areas are needed to investigate this issue and to research the relevance or possible association of point mutation and antibiotic resistance to EMB in order to be able to devise better plans for preventing antibiotic resistance in $M$. tuberculosis cases. Considering the geographic area of the present study, it is expected to obtain valuable results.

\section{Materials and Methods}

\section{Study Population}

The present research was conducted as a case-control study. Case group included isolates of $M$. tuberculosis that were resistant to EMB at least in terms of phenotype and had mutation in emb306B gene; and the control group was comprised of those types of $M$. tuberculosis isolates that were susceptible to EMB in phenotype and had no mutation in $e m b \mathrm{~B}$. According to a census carried out by the country's Drug Resistance Surveillance (DRS) program in Western part of the country in a period from 2014 to 2015, only seven samples of antibiotic-resistant $M$. tuberculosis were identified from all the antibiotic susceptibility tests. The study population included samples sent from Western provinces of Iran to the Mycobacterium Research Center as the reference laboratory, which is located in the city of Kermanshah in Kermanshah province.

\section{Identification of Samples}

Initially, sputum samples that were suspected of having TB were sanitized with Modified Petroff
Method. The samples were colored using Auramine and Ziehl-Neelsen technique. Löwenstein Jensen (LJ) agar medium (Merck, Germany) was used for culturing the samples and the colonies were studied after incubation at temperature of $37^{\circ} \mathrm{C}$ for 4 weeks. Suspicious colonies were assessed based on the speed of growth of colonies (slow growing) and by biochemical assays (positive niacin production, positive nitrite reduction, positive urease, positive thiosemicarbazon, sensitive cycloserine $20 \mu \mathrm{L} / \mathrm{mL}$ in LJ, positive oxygen performance, positive pyrazinamide activity, catalase activity at $68^{\circ} \mathrm{C}$, negative $\mathrm{NaCl}$ tolerance, and pigment production) (8).

Determining the Medicinal Sensitivity of Mycobacterium tuberculosis

A bacterial suspension was added to each of the $\mathrm{LJ}$ culture media containing EMB $(2 \mu \mathrm{g} / \mathrm{mL})$ antibiotic, and the results were examined after 28 and 48 days (in case of growth of bacteria in these media, they were considered as resistant isolates, and if no growth was observed, they were considered as sensitive isolates). Concentration rate of EMB was $0.2 \mu \mathrm{g} / \mathrm{mL}$. The standard M. tuberculosis strain (H37RV) (SinaClon, Iran) was used as quality control of the test of sensitivity to EMB (9).

\section{Identification of embB306 Gene in M. tuberculosis Isolates}

DNA was extracted using CTAB (Cetyltrimethylammonium Bromide) after deactivation at $80^{\circ} \mathrm{C}$ for $1 \mathrm{~h}$. A piece including 863 base-pairs (bp) of embB306 gene was reduplicated by PCR to determine the presence of $\mathrm{emb \textrm {B } 3 0 6}$ gene in isolates sensitive and resistant to EMB. Oligonucleotides included embB306-F (5'CGACGCCGTGGTGATATTCG-3') and embB306-R (5'-CCACGCTGGGAATTCGCTTG-3) (SinaClon, Iran). The final PCR mixture (final volume of $50 \mu \mathrm{L}$ ) consisted of $0.2 \mu$ molar of every primer, 25.1 units of Taq-polymerase enzyme (SinaClon, Iran), 0.2 mmolar dNTP, and 1 mmolar of $10 \mathrm{X}$ buffer. PCR reaction was conducted as follows: Primary denaturation for $5 \mathrm{~min}$ at $95^{\circ} \mathrm{C}$, secondary denaturation at $94^{\circ} \mathrm{C}$ for $30 \mathrm{~s}$, annealing phase at $70^{\circ} \mathrm{C}$ for $40 \mathrm{~s}$, extension at $95^{\circ} \mathrm{C}$ for $72 \mathrm{~s}$, in 30 cycles. The final extension phase was carried out at $72^{\circ} \mathrm{C}$ for $10 \mathrm{~m}$. The $\mathrm{embB}$ gene sequence was determined by means of sequence analysis (Gene Faravaran, Iran) and analysis of created point mutations in sequence of $e m b$ B306 gene was done through comparing them with the sequence of $e m b \mathrm{~B}$ gene sequence derived from the standard strain of $M$. tuberculosis H37RV provided by GeneBank (http://www.ncbi.nlm.nih.gov/genbank) using BLASTn algorithm (http://blast.nbci.nlm.nih.gov). Presence of mutations of $e m b \mathrm{~B}$ gene and point mutations were examined in sensitive and resistant strains and finally, the relationship between embB306 gene mutation and resistance to EMB was analyzed (10). 


\section{Statistical Analysis}

Frequency and percentages were determined by means of Fischer's test and SPSS 16 (SPSS Inc., Chicago, IL., USA), which were used to compare mutations in both resistant and nonresistant groups to EMB $(P \leq 0.05)$.

\section{Results}

\section{Patients}

Pulmonary specimens were obtained from 1019 patients with suspected TB. After identification of samples, 50 M. tuberculosis strains (from 22 men and 28 women with the age range of 23-86 and a median age of 54.5) were identified and then isolated to the species level. Afterward, drug susceptibility tests were carried out.

\section{Results of Antibiotic Resistance}

The number of isolates sensitive to EMB was 43 $(86 \%)$ and the number of samples resistant to EMB was $7(14 \%)$. The results of antibiotic resistance test are provided in Table 1 for both the case and control groups. The results of mutation analysis for embB306 gene in the case and control groups showed that no mutation had occurred in the control samples, but embB306 mutation was observed in six $(85.71 \%)$ out of seven samples in this gene, which were resistant to EMB (Figure 1, Table 1). Presence of mutation in embB306 gene was directly correlated with EMB and mutation in emb306 gene $(P=0.000)$.

\begin{tabular}{|c|c|c|c|}
\hline KP33/623.1_1 & 201 & 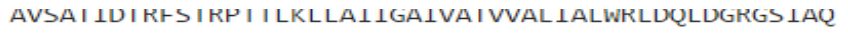 & 250 \\
\hline R6_embBR_1 & 1 & 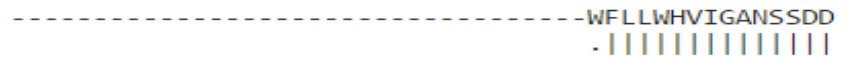 & 15 \\
\hline KP337623.1_1 & 251 & LLLRPFRPASSPGGMRRLIPASWRTFTLTDAVVIFGFLLWHVIGANSSDD & 300 \\
\hline R6_embBR_1 & 16 & $\begin{array}{l}\text { GYILGIARVADHAGYMSNYFRWFGSPEDPFGWYYNLLALMTHVSDASLWM } \\
||||||||||||||||||||||||||||||||||||||||||||||||||||||||\end{array}$ & 65 \\
\hline KP337623.1_1 & 301 & GYILGMARVADHAGYMSNYFRWFGSPEDPFGWYYNLLALMTHVSDASLWM & 350 \\
\hline R6_embBR_1 & 66 & 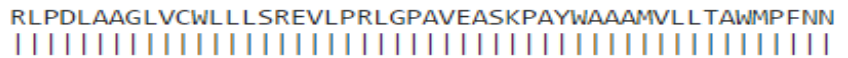 & 115 \\
\hline KP337623.1_1 & 351 & RLPDLAAGLVCWLLLSREVLPRLGPAVEASKPAYWAAAMVLLTAWMPFNN & 400 \\
\hline R6_embBR_1 & 116 & 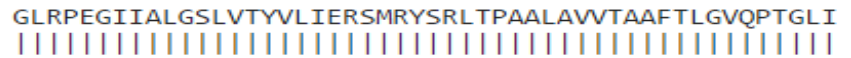 & 165 \\
\hline KP337623.1_1 & 401 & GLRPEGIIALGSLVTYVLIERSMRYSRLTPAALAWTAAFTLGVQPTGLI & 450 \\
\hline R6_embBR_1 & 166 & 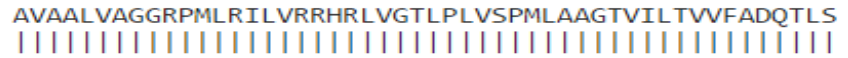 & 215 \\
\hline KP337623.1_1 & 451 & AVAALVAGGRPMLRILVRRHRLVGTLPLVSPMLAAGTVILTVVFADQTLS & 500 \\
\hline R6_embBR_1 & 216 & 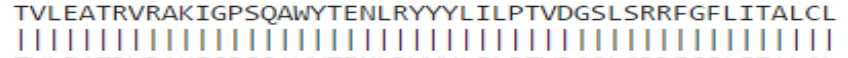 & 265 \\
\hline KP337623.1_1 & 501 & TVLEATRVRAKIGPSQAWYTENLRYYYLILPTVDGSLSRRFGFLITALCL & 550 \\
\hline R6_embBR_1 & 266 & 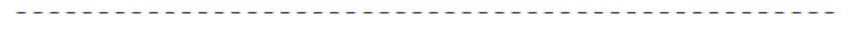 & 265 \\
\hline KP337623.1 1 & 551 & FTAVF IMLRRKRIPSVARGPAWRLMGVIFGTMFF LMFTPTKWVHHFGLFA & 600 \\
\hline KP337623.1_1 & 201 & AVSATIDTRFSTRPTTLKLLAIIGAIVATWALIALWRLDQLDGRGSIAQ & 250 \\
\hline R2_embBR_3 & 1 & 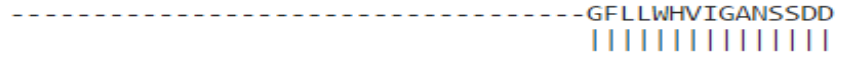 & 15 \\
\hline KP337623.1_1 & 251 & LLLRPFRPASSPGGMRRLIPASWRTFTLTDAVVIFGFLLWHVIGANSSDD & 300 \\
\hline R2_embBR_3 & 16 & $\begin{array}{l}\text { GYILGVARVADHAGYMSNYFRWFGSPEDPFGWYYNLLALMTHVSDASLWM } \\
|||||:||||||||||||||||||||||||||||||||||||||||||| \mid\end{array}$ & 65 \\
\hline KP337623.1_1 & 301 & GYILGMARVADHAGYMSNYFRWFGSPEDPFGWYYNLLALMTHVSDASLWM & 350 \\
\hline R2_embBR_3 & 66 & $\begin{array}{l}\text { RLPDLAAGLVCWLLLSREVLPRLGPAVEASKPAYWAAAMVLLTAWMPFNN } \\
||||||||||||||||||||||||||||||||||||||||||||||||||\end{array}$ & 115 \\
\hline KP337623.1_1 & 351 & RLPDLAAGLVCWLLLSREVLPRLGPAVEASKPAYWAAAMVLLTAWMPFNN & 400 \\
\hline R2_embBR_3 & 116 & $\begin{array}{l}\text { GLRPEGIIALGSLVTYVLIERSMRYSRLTPAALAVVTAAFTLGVQPTGLI } \\
||||||||||||||||||||||||||||||||||||||||||||||||\end{array}$ & 165 \\
\hline KP337623.1_1 & 401 & GLRPEGIIALGSLVTYVLIERSMRYSRLTPAALAVVTAAFTLGVQPTGLI & 450 \\
\hline R2_embBR_3 & 166 & $\begin{array}{l}\text { AVAALVAGGRPMLRILVRRHRLVGTLPLVSPMLAAGTVILTVVFADQTLS } \\
|||||||||||||||||||||||||||||||||||||||||||||| \mid\end{array}$ & 215 \\
\hline KP337623.1_1 & 451 & AVAALVAGGRPMLRILVRRHRLVGTLPLVSPMLAAGTVILTVVFADQTLS & 500 \\
\hline R2_embBR_3 & 216 & 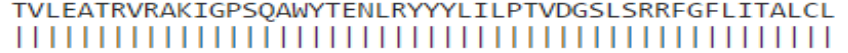 & 265 \\
\hline KP337623.1_1 & 501 & TVLEATRVRAKIGPSQAWYTENLRYYYLILPTVDGSLSRRFGFLITALCL & 550 \\
\hline R2_embBR_3 & 266 & 其, & 265 \\
\hline 1_1 & & RRKRIPSVARGPAWRLMGVIFGTMFFLMFTPTKWVHHFGLFA & \\
\hline
\end{tabular}

Figure 1. Mutated amino acid isoleucine (I) instead of methionine (M) and valine (V) instead of methionine (M) at codon 306, sequence of these amino acid was checked with H37RV according to European molecular biology laboratory (EMBL)European Bioinformatics Institute (EBI)) nBLAST algorithms 
Table 1. Point mutations (missense mutation) detected in studied EMB-resistant and EMB-susceptible M. tuberculosis isolates

\begin{tabular}{ccc} 
Nucleotide & Mutation Amino Acid & $\begin{array}{c}\text { No. (\%) of EMB-resistant mutant } \\
\text { isolates in emb306 (n=6) }\end{array}$ \\
$\mathrm{ATG} \rightarrow \mathrm{ATA}$ & Met $\rightarrow$ Il (306) & $3(42.85)$ \\
$\mathrm{ATG} \rightarrow \mathrm{GTG}$ & $\mathrm{Met} \rightarrow$ Val (306) & $3(42.85)$ \\
\hline
\end{tabular}

\section{Discussion}

In the present study, the maximum rate of identified mutations was found in embB306 gene, which belonged to the case group (EMB-resistant strains), while no mutation was found in the strains sensitive to this medication. In a study conducted in Iran, Derakhshani Nezhad et al. (2012) showed that among 106 M. tuberculosis samples, 33.9\% were resistant to EMB using the proportion method. Using Allelespecific PCR (ASPCR), 27.6\% of strains were EMB resistant. This method showed that mutation in the first base was $61.5 \%$ (Met $\rightarrow$ Val or Il) and it was $38.5 \%$ in the third base (Met $\rightarrow$ Il) (11). In the present research, six case samples out of 50 strains had mutation in the embB306 region. Determination of possible mutations with the help of PCR-sequencing is the main technique for mutation analysis in resistance-related genes. Although this technique is a time-consuming and burdensome method, it has high efficiency in terms of sensitivity and property. An accurate laboratory diagnosis of TB is the most important step in diagnosis of the disease. One of the reasons for differences in various studies is the application of different techniques with varying degrees of differentiation and sensitivity, which may lead to different results (8). In the study conducted by Bakula et al. (2013), who used PCR-sequencing, out of 50 studied strains (33 EMBsensitive strains and 17 EMB-resistant strains), six types of mutations were found in $27(54 \%)$ samples. Mutation in $e m b \mathrm{~B}$ gene was observed among 13 (76.5\%) EMB-resistant strains and 14 (42.4\%) EMBsensitive strains (1). Unlike Bakula's study, the current work showed no mutation in EMB-sensitive strains; and among the seven EMB-resistant samples, all of them had mutation in the embB306 region. A strong relationship was observed between embB306 mutants and resistance to EMB. The study's results showed that mutation in $e m b \mathrm{~B} 306$ gene is an important indicator for detection of resistance to EMB. In conclusion, it was demonstrated that embB306 mutation is a common polymorphism in the strains resistant to EMB $M$. tuberculosis. Considering that only isolates resistant to EMB were studied in this work, further evaluation of a number of EMB-susceptible and resistant isolates from different geographic regions is required to explicate the role of these mutations in resistance to EMB. In addition, even though under normal conditions, definitive diagnosis of resistance to a drug requires about 42 days, it can be diagnosed in only 6-7 days by means of molecular techniques. Quick diagnosis of drug resistance may prevent wrong administration of drugs and it also leads to employing the proper therapeutic diet that prevents the spread of multiple drug-resistant (MDR) strains, which is a large issue $(12,13)$. Using phenotypic susceptibility testing, Khosravi et al. showed that resistance to emb was $3.25 \%$ in Iran. Rate of mutation in $e m b B$ was $10 \%$ at codon $306 \mathrm{Met} \rightarrow \mathrm{Val}$ (12). It has been found that mutations in $e m b B 306$ of $e m b B$ gene very often occur among other codons. High detection rates of mutation have been reported in codon embB306 among EMBresistant $M$. tuberculosis isolates in various countries (1). Therefore, in this study, embB306 was investigated among other genes by PCR-Sequencing. PCR is a rapid method with high discriminatory capabilities, and it is easy to use while being obtainable at a low cost $(14,15)$. Moreover, limitations of this research are as follows: The small number of antibiotic-resistant specimens, especially samples with resistance to EMB in the studied area, the high cost of molecular testing equipment and tools, slow growth of bacteria in a specific culture medium and special incubation conditions, and due to the high contamination level of M. tuberculosis, sampling and DNA extraction should be performed under conditions of high immunity and level 3 safety. Given that $e m b \mathrm{~B}$ gene mutations, especially those located in ERDR, are considered as "hot-spots", they have been repeatedly investigated in studies concerned with EMB-resistance in $M$. tuberculosis cases. Therefore, the PCR-Sequencing method is a precise method for determining these hotspots. Moreover, mutation rates in first and third bases were very similar to each other. In addition, it was observed that embB306 mutations were present only in isolates that were resistant to EMB and had a significantly higher proportion of embB306 mutants.

\section{Conclusion}

The majority of EMB-resistant isolates showed embB306 mutation. No embB306 mutant was detected among the susceptible strains. The current study demonstrated that mutation in embB306 can be considered as an indicator of resistance to EMB in isolates of M. tuberculosis, and most of the found mutations were located in this codon. However, mutations in embB306 are not the main reason for resistance to EMB in isolates; other mechanisms of resistance in $\mathrm{M}$. tuberculosis should be considered as well. 


\section{Acknowledgments}

This paper is part of Mr. Bahman Mohammadi's (MSc of medical microbiology) project under the code 1394/261, approved by the Research Committee of Kurdistan University of Medical Sciences, who supported this project financially. We would like to send our appreciation to those who showed special attention to this work. We would also like to thank and appreciate Ms. Sara Atashi and Mr. Galini for their fabulous technical assistance.

\section{Conflict of Interest}

Authors declared no conflict of interest.

\section{References}

1. Bakula Z, Napiorkowska A, Bielecki J, Augustynowicz-Kopec E, Zwolska Z, Jagielski T. Mutations in the embB gene and their association with ethambutol resistance in multidrug-resistant Mycobacterium tuberculosis clinical isolates from Poland. Biomed Res Int 2013;2013(2013):167954.

[DOI:10.1155/2013/167954] [PMID] [PMCID]

2. Watford S, Warrington SJ. Bacterial DNA mutations. Treasure Island (FL), StatPearls Publishing; 2019.

3. Brossier F, Sougakoff W, Bernard C, et al. Molecular analysis of the embCAB locus and embR gene involved in ethambutol resistance in clinical isolates of Mycobacterium tuberculosis in France. Antimicrob Agents Chemother. 2015; 59(8):4800-8. [DOI:10.1128/AAC.00150-15] [PMID] [PMCID]

4. Guerrero E1, Lemus D, Yzquierdo S, et al. Association between embB mutations and ethambutol resistance in Mycobacterium tuberculosis isolates from Cuba and the Dominican Republic: reproducible patterns and problems. Rev Argent Microbiol. 2013;45(1):216.

5. Cuevas-Córdoba B, Juárez-Eusebio DM, Almaraz-Velasco R, Muñiz-Salazar R, LaniadoLaborin R, Zenteno-Cuevas R. Mutation at embB Codon 306, a potential marker for the identification of multidrug resistance associated with ethambutol in Mycobacterium tuberculosis. Antimicrob Agents Chemother. 2015;59(9):545562. [DOI:10.1128/AAC.00117-15] [PMID] [PMCID]
6. Nasr Esfahani B, Zarkesh FS, Rezaei Yazdi H, Radaee T. Detection of embB gene mutations in EMB-resistant Mycobacterium tuberculosis isolates from Isfahan province by PCR-SSCP and direct sequencing. Jundishapur J Microbiol. 2016;9(12);e39594. [DOI:10.5812/jjm.39594]

7. Ahmad B, Idrees M, Ahmad K, Bashir S, Ahmad $\mathrm{S}$, Lin-Fang H. Mutation analysis for detection of drug resistance in mycobacterium tuberculosis isolates from Khyber Pakhtunkhwa, Pakistan. J Pak Med Assoc. 2017;67(11):1684-8.

8. Azadi D, Shojaei H. The role of the laboratory in the diagnosis of tuberculosis. Iran $\mathrm{J}$ Med Microbiol. 2016;10(2):1 -15.

9. Gül Yurtsever S, Biçmen C, Gündüz AT, Ozkütük N, Salman S, Demirci M. Comparison of proportion method in Löwenstein-Jensen medium with the BACTEC 460 TB system for antimycobacterial susceptibility testing of Mycobacterium tuberculosis isolates. Mikrobiyol Bul. 2011;45(4):623-31.

10. Rezai MS, Ahangarkani F, Sadeghi R, Mahdavi MR. Evaluation of children with complication of BCG vaccination in north of Iran. Int $\mathbf{J}$ Pediatr 2017;5(3):1795-805.

11. Derakhshani Nezhad Z, Sheikolslami FM, Farnia $\mathrm{P}$, et al. Identification and genetic diversity of etambutol resistant strains of mycobacterium tuberculosis by allelic-specific PCR and spologiotyping. J Ardabil Univ Med Sci. 2012;12(3):248-55. [In Persian]

12. Khosravi AD,Sirous MD, Abdi M, Ahmadkhosravi N.Characterization of the most common embCAB gene mutations associated with ethambutol resistance in Mycobacterium tuberculosis isolates from Iran. Infect Drug Resist. 2019; $\quad 12 \quad$ (2019): $\quad$ 579-584. [DOI:10.2147/IDR.S196800] [PMID] [PMCID]

13. Ramazanzadeh R, Roshani D, Roohi S, Mohammadi B. Prevalence of multi-drug resistance Mycobacterium tuberculosis in world population: systematic review and meta-analysis. Int J Mycobacteriol. 2015;4(1):113. [DOI:10.1016/j.ijmyco.2014.11.060]

14. Rouhi S, Ramazanzadeh R, Nouri B. Genotyping, pandrug resistance, extensively drug-resistant, and multi drug-resistance detection of pseudomonas aeruginosa isolated from patients in the west of Iran.Cres J Med Biol Sci. 2019;6(2):170-177.

15. Ricke SC, Feye KM, Chaney WE, Shi Z, Pavlidis $\mathrm{H}$, Yang Y. Developments in rapid detection methods for the detection of foodborne campylobacter in the United States. Front Microbiol. 2019;9 (2019):3280. [DOI:10.3389/fmicb.2018.03280] [PMID] [PMCID] 


\section{How to Cite This Article:}

Mohammadi B, Ramazanzadeh R, Rouhi S, Mohajeri P, Nouri B. Point-Mutations in embB306 Gene and Their Association with Resistance to Ethambutol in Mycobacterium tuberculosis in Clinical Isolates. J Adv Med Biomed Res. 2019; 27 (125) :43-48

\section{Download citation:}

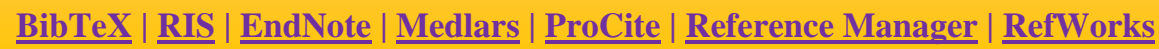

\section{Send citation to:}

Mendeley 2 Zotero (2)RefWorks $\underline{\text { RefWorks }}$ 